\title{
Compatibilização de projeto arquitetônico, estrutural e sanitário: Uma abordagem teórica e estudo de caso.
}

\author{
Compatibility of architectural, structural and health design: A theoretical approach and a case study.
}

\author{
Almir Mariano de Sousa Junior', Clivia Corina Lima Lobo Maia², \\ Prisciliane Roberta Paula de Azevedo Correio ${ }^{3}$ \\ 'Mestre em Engenharia de Petróleo e Gás Natural, Professor da Universidade Federal Rural do Semi-árido - UFERSA - RN - Brasil. \\ ${ }^{2}$ Universidade Potiguar (UnP) - RN - Brasil.
}

\begin{abstract}
Resumo
A urgente necessidade da valorização da atividade de projeto e gestão de projeto tem se destacado no âmbito dos novos avanços e dinâmicas que a construção civil vem adotando no país. Quando atividade de projeto e relegada para segundo plano os erros e patologias nas edificações são indicativos da necessidade de compatibilização de projetos, a fim de amenizar os altos índices de retrabalhos e desperdícios. Embora os diversos avanços nas ferramentas que viabilizam a compatibilização entre projetos, ainda são notórias as dificuldades que algumas empresas têm em adotar, sejam por fatores financeiros ou por desconhecimento da importância da gestão de projetos. No intuito de apresentar a problemática abordada neste artigo, foram utilizadas pesquisas bibliográficas em trabalhos de diversos estudiosos e pesquisadores que abordam o tema da importância da compatibilização de projetos. Foi apresentado também um estudo de caso, onde foram avaliadas e demonstradas as interferências entre projetos de arquitetura e estrutura com os demais projetos complementares. Foi constatado durante a compatibilização realizada que os projetos possuíam diversas interferências entre si que certamente ocasionariam retrabalhos e diversas decisões não planejadas, que seriam tomadas durante a execução da obra no intuito de reparar as diversas interferências devidas a falta de compatibilização.
\end{abstract}

Palavras-chave: Compatibilização; Gestão de projetos; Importância dos projetos.

\begin{abstract}
The urgent need for the valuation of the project activity and project management has been highlighted in the context of new developments and dynamics that construction has been taking the country. When the project activity and relegated to the background errors and pathology in buildings are indicative of the need for compatibility of projects in order to mitigate the high levels of rework and waste. Although many advances in tools that enable compatibility between projects, are still considerable difficulties that some companies have to adopt , by financial factors or are unaware of the importance of project management. In order to present the issues addressed in this monograph , literature searches were used in the works of several scholars and researchers that address the importance of compatibility of projects . A case study, where they were evaluated and demonstrated interferences between architectural design and structure with other complementary projects was also presented. Were detected during the reconciliation accomplished that projects had several interferences between them which certainly would provoke various unplanned rework and decisions that would be taken during the execution of the work in order to repair the various interferences due to lack of compatibility.
\end{abstract}

Keywords: Compatibility; Project Management; Importance of projects. 


\section{INTRODUÇ̃̃O}

O presente trabalho apresenta a compatibilização dos projetos de arquitetura e complementares a fim de identificar as interferências entre si e buscar soluções para corrigir as incompatibilidades.

O processo de desenvolvimento dos projetos foi realizado de maneira sequencial, onde o empreendedor contratou profissionais específicos que trabalhavam em escritórios isolados, desse modo cada escritório contratado ficou responsável por desenvolver determinado tipo de projeto. Um escritório de arquitetura ficou responsável pela elaboração dos projetos de arquitetura e acessibilidade.

$\mathrm{O}$ projeto de arquitetura foi o primeiro a ser realizado. Após a elaboração do anteprojeto e aprovação do cliente, foi desenvolvido o projeto definitivo para aprovação mediante os órgãos fiscalizadores, sendo estes a Prefeitura e a Secretaria de Meio Ambiente.

Após a provação Legal do projeto de Arquitetura, o projeto digital de arquitetura foi enviado através de correio eletrônico aos demais escritórios, para que os demais profissionais contratados dessem sequencia ao processo de projeto sequencial. Assim, um escritório comandado por um engenheiro civil elaborou os projetos de instalações hidráulicas e sanitárias, outro ficou responsável pela elaboração do projeto de instalações elétricas e projeto de múltiplas unidades de medição de energia. Um terceiro escritório, comandado por três engenheiros civis, se responsabilizou pelos projetos de estrutura do edifício. Ainda não foram elaborados os projetos de Prevenção e Combate á Incêndio e Pânico e SPDA (Sistema De Proteção De Descargas Atmosféricas).

Os projetos encontram-se na fase de estudo e aperfeiçoamento, portanto este estudo foi realizado em projetos finalizados, porém não executados ainda, sendo possíveis as correções das incompatibilidades de projetos para a finalização do projeto executivo.

Todos os projetistas envolvidos, arquitetos e engenheiros, utilizaram-se das ferramentas CAD para desenvolvimento dos projetos e a apresentação dos projetos em $2 \mathrm{D}$. No projeto de arquitetura foram ainda utilizadas outras ferramentas de representação como o CAD 3D, para elaboração de maquetes eletrônicas e renderizadores $3 \mathrm{D}$, para elaboração de perspectivas ilustrativas do empreendimento. Todo esse material gráfico foi utilizado para confecção de material midiático para material de publicidade do empreendimento.

\section{A IMPORTÂNCIA DO PROJETO}

O setor da construção civil vem recebendo uma demanda crescente de investimentos públicos e privados em obras pesadas. Tendo em vista que muitos dos problemas relacionados á falta de qualidade em edificações, tem como causa principal um processo de projeto informal, setores da construção civil têm buscado, ainda de forma principiante, metodologias de gestão da atividade de projeto, no sentido de modificar, melhorar e aperfeiçoar o modelo convencional e garantir a qualidade de seus produtos e processos, tendo como principais consequências um produto final de qualidade e satisfação do cliente.

Onde a fase de projeto desempenha fator determinante em um empreendimento de construção civil, pois possibilita o mapeamento das probabilidades pré-execução, melhoramentos de métodos de execução, interferências e possíveis patologias decorrentes, auxiliando na detecção de problemas e assim reduzindo o índice de desperdícios e retrabalhos, aumentando ganhos financeiros durante sua construção.

Para muitas empresas brasileiras o projeto ainda é visto como um custo mais, em função de valores financeiros relocados para sua elaboração e a resistência em seguir as exigências legais. Segundo Melhado (2004) isto se dá devido ao fato de no Brasil não existir a cultura que se tem nos países desenvolvidos, onde o tempo de projeto muitas vezes chaga a ser da mesma ordem de grandeza do tempo dedicado á obra, procurando-se com isso eliminar ou mesmo reduzir as deficiências e os desperdícios comuns na fase de execução da obra.

Vários autores apontam para um consenso de considerar a fase inicial do empreendimento como o mais importante, pois é nesta fase que se encontram as oportunidades de reduzir a quantidade de falhas e consequentemente reduzirem os custos do empreendimento.

Para Hammarlund e Josephson (1992) as decisões que influenciam na redução de custos do empreendimento devem ser tomadas na fase inicial do mesmo, pois com a evolução de suas etapas, a possibilidade de influenciar no custo final do empreendimento diminui consideravelmente.

O momento ideal para tomadas de decisões e definições de equipes de construção é na fase de projeto. Os estudos de projetos bem elaborados proporcionam uma melhor gestão de obras, amenizando os impactos gerados pelas decisões em canteiros e os altos índices de retrabalhos resultantes no mau planejamento dos projetos. Projetos mal elaborados contribuem para o alongamento 
dos prazos das obras e como consequência os acréscimos do custo final da obra. O impacto das mudanças nas construções são maiores quanto mais se avança no processo construtivo. Portanto decisões na fase de projetos pode influenciar todo o ciclo de vida do empreendimento.

De acordo com a pesquisa de Hammarlund; Josephson (1992), o projeto aparece como principal causa das falhas de funcionamento das edificações, sendo a origem de $51 \%$ dos problemas.

Apesar dessa importância que o projeto tem para determinar e influenciar os custos, a qualidade e o desenvolvimento do empreendimento em geral, os projetos de edificações brasileiras, são vistos por algumas empresas como custos, que na verdade deveriam ser vistos como investimentos. E, contudo na maioria das vezes, são desenvolvidos por escritórios que não pertencem ao organograma da empresa construtora, ou seja, são empresas subcontratadas para prestarem serviços à construtora. Com isso, muitas vezes, o projeto é contratado segundo critérios de preço do serviço, sem levar em conta questões como a qualidade e a integração entre os diversos projetos, e entre projetos e o sistema de produção da empresa.

O projeto deve ser entendido como parte integrante do processo de construção. A partir dessa problemática verifica-se a importância dos projetos, no âmbito de informações, desenvolvimento, organização, registro, transmissão das características físicas e tecnológicas especificas para uma obra, e auxilio no planejamento de etapas executivas em uma obra, posto que fornece os requisitos geométricos e técnicos fundamentais ao processo de construção. Tudo de modo a atender as necessidades e exigências requeridas, buscando soluções para os problemas de construção do produto final.

\section{COMPATIBILIZAÇÃO DE PROJETOS}

Novaes (1998) ainda afirma que é necessário a participação dos diversos profissionais de projetos envolvidos nas etapas de execução do empreendimento, que resultarão em maior entendimento das etapas construtivas e desse modo permitirão a "elaboração de projetos futuros com redução de incertezas, pela maior proximidade com a realidade produtiva."

Compatibilizar projetos é verificar se os componentes dos sistemas ocupam espaços não conflitantes entre si e, além disso, garantir que os dados compartilhados tenham consistência e confiabilidade até o final do projeto (GRAZIANO,2003).
Do ponto de vista especifico da compatibilização de projetos, inúmeras são suas definições, embasadas em vários estudos realizados. Em geral todos relacionados com o bom desempenho do projeto em termos de tempo custo e qualidade.

Portanto, compatibilização de projetos é a atividade que torna os projetos compatíveis, estabelecendo soluções integradas entre as diversas áreas que tornam um empreendimento factível.

\section{RELEVÂNCIA DA COMPATIBILIZA- ÇÃO}

Segundo Castro (1999), um dos problemas mais comuns nas diversas manifestações patológicas encontradas em edificações estruturadas em aço, é a interferência entre projeto estrutural e os projetos de instalações. Esta interferência é proveniente de incompatibilidades de projetos ou de modificações no decorrer da construção, devido principalmente a falta de uma maior coordenação entre os diversos sistemas construtivos envolvidos.

Devido ao hábito de não racionalizar materiais, em grande parte das obras e normalmente contextualizada como a separação do projeto e a execução, é reflexo do desenvolvimento do setor nos últimos 30 anos conforme relatado por (GRAZIANO 2003).

Para Rodriguez (2005 apud MIKALDO JR. 2006), a melhoria do processo será alcançada apenas com ações que estimulem a formação de equipes cooperativas de trabalho e a integração entre o projeto e a produção. Sugere que as relações contratuais são a ferramenta que deve consolidar esta forma de atuação.

Fazem-se necessário a coordenação e compatibilização dos projetos, devido principalmente a segregação do projeto e execução. Conforme Mikaldo Jr. (2006) cita como agentes geradores de necessidade de compatibilização:

Graziano (2003) atribui a responsabilidade da compatibilização de projetos para os clientes e projetistas e apresenta exemplos atuais, como:

\section{METODOLOGIA}

Para fundamentar a relevância do tema, o estudo de caso tem um papel relevante em exercícios de construção da teoria, desse modo procura-se verificar e atestar a fundamentação teórica defendida desde a escolha do tema. As analises realizadas durante o estude de caso referem-se aos projetos 
Tabela 1 - Tabela com os agentes geradores.

\begin{tabular}{|l|l|l|l|}
\hline 1. & $\begin{array}{l}\text { Número crescente de soluções tecnológicas sendo agregadas nos } \\
\text { empreendimentos. }\end{array}$ \\
\hline 2. & Especialização cada vez maior das diferentes áreas de projetos; \\
\hline 3. & Conformação de equipes de projeto localizadas em diferentes localidades; \\
\hline
\end{tabular}

Fonte: Autoria própria

Tabela 2 - Tabela de responsabilidades Projetista x clientes.

\begin{tabular}{|l|l|l|}
\hline Item & Responsabilidade do projetista & Responsabilidade do cliente \\
\hline 1. & $\begin{array}{l}\text { Descomprometimento com a } \\
\text { interação; }\end{array}$ & $\begin{array}{l}\text { Fornecimento de informações incompletas e } \\
\text { incorretas como embasamento para o } \\
\text { desenvolvimento do projeto; }\end{array}$ \\
\hline 2. & $\begin{array}{l}\text { Pouco conhecimento com as } \\
\text { técnicas construtivas da obra; }\end{array}$ & $\begin{array}{l}\text { Falta de componente capacitado para análise } \\
\text { técnica dos diversos projetos e tomadas de } \\
\text { decisões; }\end{array}$ \\
\hline 3. & $\begin{array}{l}\text { Falta de interesse e ausência de } \\
\text { conhecimento sobre os demais } \\
\text { projetos; }\end{array}$ & $\begin{array}{l}\text { Postergação de decisões que influenciam no } \\
\text { desenvolvimento dos projetos; }\end{array}$ \\
\hline
\end{tabular}

Fonte: Autoria própria.

de um edifício residencial multifamiliar que está em fase de elaboração dos mesmos. Porém foram fornecidos projetos já finalizados, sendo estes o arquitetônico, estrutural e instalações hidrossanitárias. Desse modo será realizada a analise das compatibilizações dos projetos Arquitetônico/ estrutural com projeto hidráulico;

Mediante a ausência de ferramentas mais bem elaboradas de compatibilização, e as limitações de apresentação de projetos que estão em unanimidade no formato AutoCAD 2D, foi utilizado o programa AutoCAD e realizada a compatibilização em nível 2D.

Os projetos foram elaborados de forma sequencial, tendo o projeto de arquitetura como a base para elaboração e desenvolvimento dos demais projetos. As tecnologias de informação utilizadas para desenvolvimento dos projetos descrevem-se quadro abaixo:

O projeto de arquitetura foi desenvolvido com auxilio do software Autocad com modelagem em 2D. O projeto estrutural foi desenvolvido com o auxilio do software CAD/TQS com modelagem da estrutura em 2D.

\section{ESTUDO DE CASO}

Com o objetivo de realizar a compatibilização entre projetos e identificar as incompatibilidades, o estudo de caso foi realizado em projetos de um edifício residencial multifamiliar, inserido em uma área de $2.800,00 \mathrm{~m}^{2}$.

$\mathrm{O}$ empreendimento constitui-se de cinco blocos de edifício, cada um com quatro pavimentos de apartamento e mais um que é a cobertura e reservatório de água superior. Sendo o pavimento térreo, $1^{\circ}$ pavimento, $2^{\circ}$ pavimento e $3^{\circ}$ pavimento compostos por quatro apartamentos cada, totalizando 16 apartamentos por bloco e 80 apartamentos no total do empreendimento.

Cada pavimento possui dois tipos de apartamentos, com pequena variação de área. Os apartamentos Tipo 1 e Tipo 3 possuem área construída de $55,05 \mathrm{~m}^{2}$. Já os apartamentos Tipo 2 e Tipo 4 possuem área construída de $54,07 \mathrm{~m}^{2}$. A arquitetura dos apartamentos é padronizada com sala de estar, cozinha, área de serviço, dormitório, bwc social e suíte. Este padrão se repete em todos os pavimentos e nos demais blocos.

A área total de construção do empreendi- 
Quadro 1: tecnologias empregadas para elaboração dos projetos

\begin{tabular}{|l|c|}
\hline Desenvolvimento dos projetos & Arranjo sequencial \\
\hline Diretrizes & Definidas pelo contratante \\
\hline Troca de informações & E-mail / Arquivos digitais \\
\hline \multirow{4}{*}{ Modelagem e dimensionamento } & Projeto de Arquitetura: AutoCAD \\
& 2D; Projeto Estrutural: Software \\
& CAD/TQS; \\
& Projeto Elétrico: Lumine V4; \\
& Projeto Hidrossanitário: \\
& Autocad/TigreCad \\
\hline & Projeto de Arquitetura: AutoCAD \\
& 2D; \\
Detalhamento & Projeto Estrutural: \\
& CAD/TQS; \\
& Projeto Elétrico: Lumine V4; \\
& Autocad/TigreCad \\
\hline Portal Colaborativo (Extranet) & Não foi utilizado \\
\hline Compatibilização das informações & Não houve compatibilização \\
\hline
\end{tabular}

Fonte: Autoria própria

mento é de $4146,56 \mathrm{~m}^{2}$, inserido em um terreno com $2800,00 \mathrm{~m}^{2}$ e a área de cobertura é de $1238,69 \mathrm{~m}^{2}$.

\section{CONFORMIDADE DOS PROJETOS}

Os programas utilizados para o auxilio no desenvolvimento dos projetos disponibilizam um conjunto de recursos e tipos de linhas, cores de linha, hachuras, fontes, textos, setas, marcações, espessuras, todos com configurações preestabelecidas, que quando aceitas pelo projetista acabam por criar um sistema de representação própria. Cada escritório de projetos possui padronização de penas, layers e cores próprias. Como cada escritório fiou responsável por desenvolver um determinado tipo de projeto não há uma preocupação na padronização com outros escritórios dos layers e cores que serão utilizados para identificar os elementos de desenho, nas fontes que discriminam os elementos de projeto, padronização das espessuras das linhas que representam os elementos e nas escalas dos projetos. Por isso foi necessário a devida compatibilização inicial dos layers e cores, das escalas e linhas.

\section{COMPATIBILIZAÇÃO DOS PROJETOS}

$\mathrm{Na}$ analise de incompatibilidades entre projetos, verificam-se as incompatibilidades físicas e funcionais entre os projetos de arquitetura, estrutural e instalações hidrossanitárias, através de elementos conflitantes. As verificações realizadas entre projetos deu-se através da sobreposição digital das plantas baixas dos diversos projetos no plano 2D, com o auxilio do software AutoCAD, em função da disponibilidade dos projetos de forma unanime apenas em 2D. Durante a sobreposição e analise dos projetos foram realizados os ajustes necessários que deverão se encaminhados aos projetistas para ajustes dos projetos executivos de cada tipo de projeto.

\section{COMPATIBILIZAÇÃO ENTRE O PRO- JETO ARQUITETÔNICO/ ESTRUTURAL E O PROJETO SANITÁRIO}

Os projetos de arquiteturas e de estrutura participaram da compatibilização sobrepostos, pois é importante verificar o quanto os elementos dos demais projetos irão interferir na estética (arquitetura) e sustentação do edifício( estrutura). A compatibilização realizou-se sobrepondo a planta baixa de arquitetura/Estrutura de pavimento tipo sobre a planta baixa de instalações sanitárias do pavimento tipo. Foi realizada a limpeza nos desenhos para 
Figura 6: Planta baixa do pavimento tipo

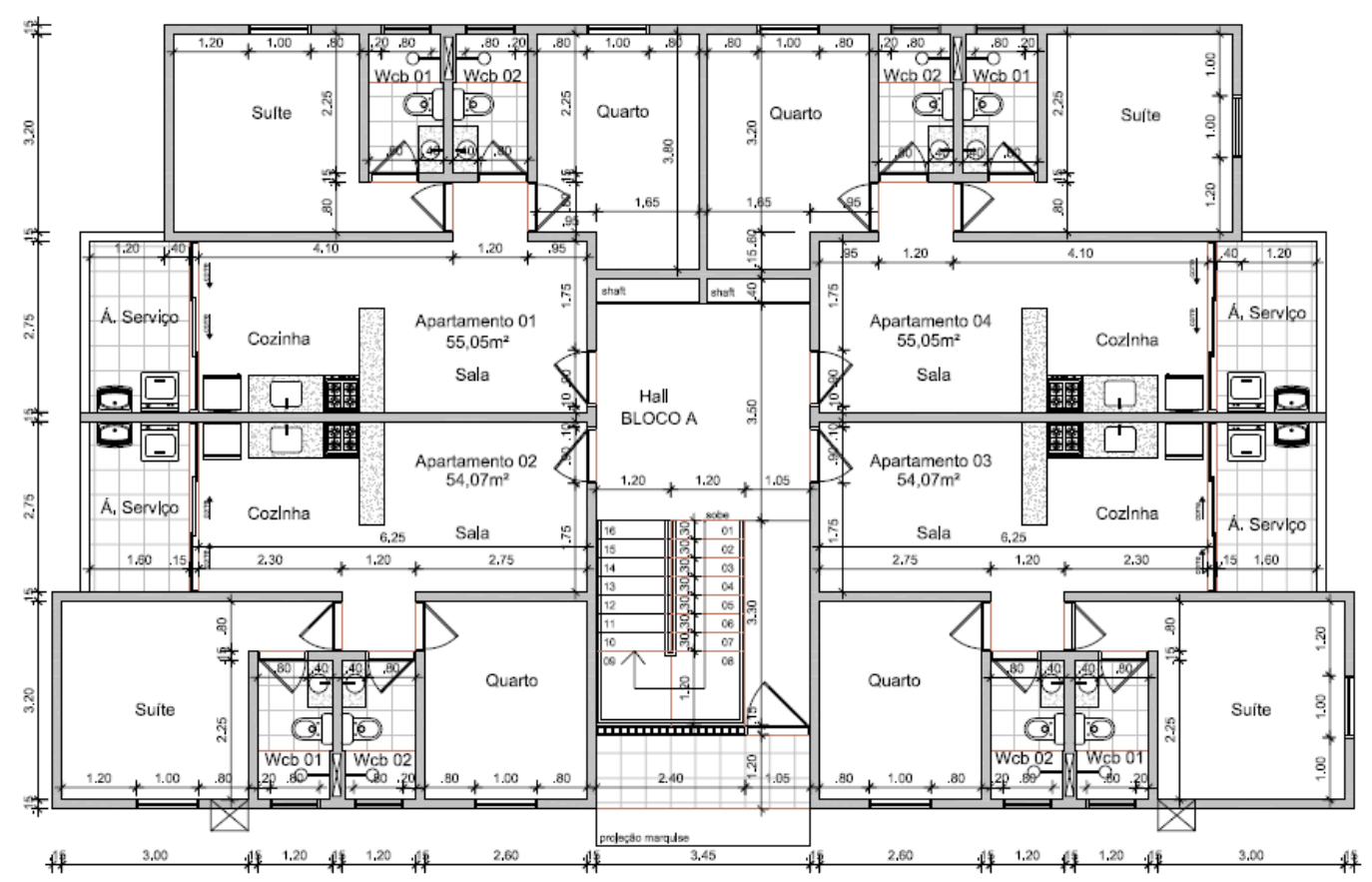

Fonte: Projeto de Arquitetura, 2013

destacar os elementos arquitetônicos e estruturais significativos e passiveis de interferência com os elementos do projeto de instalações. Depois da escolha dos elementos de projeto, criaram-se dois blocos das plantas em evidencia com o comando do AutoCAD "Draw Block", que permite a criação de blocos que podem ser editados, Depois de criados os blocos foram sobrepontos para analise das interferências. Através da verificação de incompatibilidades entre elementos do projeto de arquitetura/Estrutura e do projeto de instalações do pavimento tipo, realizou-se uma análise das interferências físicas.

Na verificação registrada no quadro acima, são apresentadas as principais interferências físicas e funcionais detectadas na compatibilização entre os projetos de arquitetura/estrutura e o projeto de instalações sanitárias. Observam-se as incompatibilidades entre os elementos conflitantes através de uma analise direta entre os elementos da estrutura (pilares, vigas e lajes) e os elementos da arquitetura (paredes, esquadrias e circulações).

Interferência direta dos tubos de queda de esgotos nos pilares P2, P4, P22 e P25, ocasionando redução do espaço destinado ao Box do bwc, tubos de queda atravessando lajes e pilares. Todas essas interferências danificam a estrutura prevista em projeto de estruturas, problema este que seria solucionado se o projetista adotasse os shafts para locação dos tubos de queda de esgotos sanitários.

Um item relevante observado na avaliação das interferências foi a inexistência de coluna de ventilação dos esgotos, ou caso houvesse, não estava identificado em projeto. $\mathrm{O}$ que caracteriza uma falha de informações que comprometem a qualidade do projeto e como consequência a qualidade do produto final.

Outro ponto relevante foi a inexistência de drenagem dos aparelhos de ar condicionado e a drenagem dos telhados que também não foi contemplada nos projetos hidrossanitários.

\section{CONCLUSÕES}

Ao final deste trabalho ficou evidenciada a importância do estudo da mecânica da fratura, em seus diferentes métodos e técnicas. Quanto ao objetivo específico do trabalho que era determinar a validade do uso da correlação de imagens na determinação de abertura de entalhe em ensaio monotônico de flexão em três pontos, as dificuldades encontradas na realização dos ensaios e a pouca quantidade de corpos de prova resultaram em resultados discrepantes e inconclusivos.

Em se tratando de um trabalho inicial e precursor, não é de todo frustrante, restando elencar pontos de melhoria para estudos futuros.

Utilizar máquina de ensaios mais bem 
Quadro 3: Análise de incompatibilidades - Arquitetura/estrutura x projeto sanitário - pavimento Tipo.

\begin{tabular}{|c|c|c|c|c|}
\hline $\begin{array}{l}\text { Elementos } \\
\text { da Arq./ } \\
\text { Estrutura }\end{array}$ & $\begin{array}{l}\text { Elementos } \\
\text { das } \\
\text { instalações } \\
\text { sanitárias }\end{array}$ & $\begin{array}{l}\text { Interf. Física } \\
\text { /Funcional } \\
\text { (falha) }\end{array}$ & Causa & Efeito \\
\hline \multirow{4}{*}{$\begin{array}{l}\text { Paredes/ } \\
\text { Pilares }\end{array}$} & Esgoto & Incompatível & $\begin{array}{l}\text { Interferência dos } \\
\text { tubos de queda } \\
\text { nos pilares: P2, } \\
\text { P4, P22 e P25 }\end{array}$ & $\begin{array}{l}\text { a)Interferência das } \\
\text { tubulações nos pilares, } \\
\text { causando retrabalhos } \\
\text { para nova locação das } \\
\text { tubulações. }\end{array}$ \\
\hline & $\begin{array}{l}\text { Coluna de } \\
\text { ventilação }\end{array}$ & Inexistente & Não prevista & $\begin{array}{l}\text { a)Inviabiliza a remoção } \\
\text { dos gases tóxicos das } \\
\text { tubulações. }\end{array}$ \\
\hline & $\begin{array}{l}\text { Drenagem } \\
\text { pluvial } \\
\text { telhados }\end{array}$ & Inexistente & $\begin{array}{l}\text { Não foi } \\
\text { considerada a } \\
\text { drenagem pluvial } \\
\text { dos telhados }\end{array}$ & $\begin{array}{l}\text { a)Decisões tomadas em } \\
\text { canteiro e obras e } \\
\text { diversas interferências } \\
\text { não previstas em projetos }\end{array}$ \\
\hline & $\begin{array}{l}\text { Drenagem dos } \\
\text { aparelhos de } \\
\text { ar } \\
\text { condicionado }\end{array}$ & Inexistente & $\begin{array}{l}\text { Não foi prevista } \\
\text { em projeto a } \\
\text { drenagem dos } \\
\text { aparelhos de ar } \\
\text { condicionado }\end{array}$ & $\begin{array}{l}\text { a)Decisões tomadas em } \\
\text { canteiro e obras e } \\
\text { diversas interferências } \\
\text { não previstas em projetos }\end{array}$ \\
\hline \multirow[b]{4}{*}{ Vigas } & Esgoto & Compatível & - & - \\
\hline & $\begin{array}{l}\text { Coluna de } \\
\text { ventilação }\end{array}$ & Compatível & Não prevista & $\begin{array}{l}\text { a)Inviabiliza a remoção } \\
\text { dos gases tóxicos das } \\
\text { tubulações de esgotos. }\end{array}$ \\
\hline & $\begin{array}{c}\text { Tubo de } \\
\text { queda }\end{array}$ & Compatível & - & - \\
\hline & $\begin{array}{l}\text { Drenagem } \\
\text { pluvial } \\
\text { telhados }\end{array}$ & Inexistente & $\begin{array}{l}\text { Não foi } \\
\text { considerada a } \\
\text { drenagem pluvial } \\
\text { dos telhados }\end{array}$ & $\begin{array}{l}\text { a)Decisões tomadas em } \\
\text { canteiro e obras e } \\
\text { diversas interferências } \\
\text { não previstas em projetos }\end{array}$ \\
\hline \multirow[b]{3}{*}{ Shafts } & Esgoto & Incompatível & $\begin{array}{l}\text { Não foram } \\
\text { utilizados os } \\
\text { shafts previstos } \\
\text { em projeto de } \\
\text { arquitetura }\end{array}$ & $\begin{array}{l}\text { a)Elementos de } \\
\text { instalações sanitárias } \\
\text { interferindo em pilares } \\
\text { (elementos estruturais) }\end{array}$ \\
\hline & $\begin{array}{l}\text { Coluna de } \\
\text { ventilação }\end{array}$ & Inexistente & - & 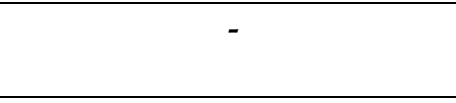 \\
\hline & $\begin{array}{l}\text { Tubo de } \\
\text { queda }\end{array}$ & Incompatível & $\begin{array}{c}\text { Tubo de queda } \\
\text { não inserido no } \\
\text { shaft }\end{array}$ & $\begin{array}{l}\text { a)Redução do espaço } \\
\text { destinado ao Box do Bwc } \\
\text { b) Tubos de queda } \\
\text { atravessando lajes, de } \\
\text { maneira não prevista em } \\
\text { projeto; } \\
\text { c) Corte desnecessário da } \\
\text { ferragem dos pilares } \\
\text { d) gasto de tempo para } \\
\text { perfurar todas as lajes } \\
\text { onde o tubo passa. }\end{array}$ \\
\hline
\end{tabular}

Fonte: autoria própria 
Figura 9: Interferências dos tubos de queda em elementos estruturais e desprezo do shaft.

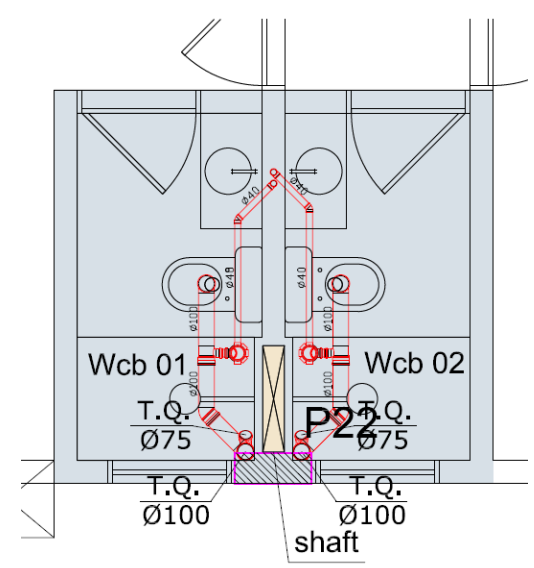

Fonte: Autoria própria

Figura 10: Principais interferências constatadas durante analise de compatibilização entre projeto de arquitetura/estrutura x sanitário.

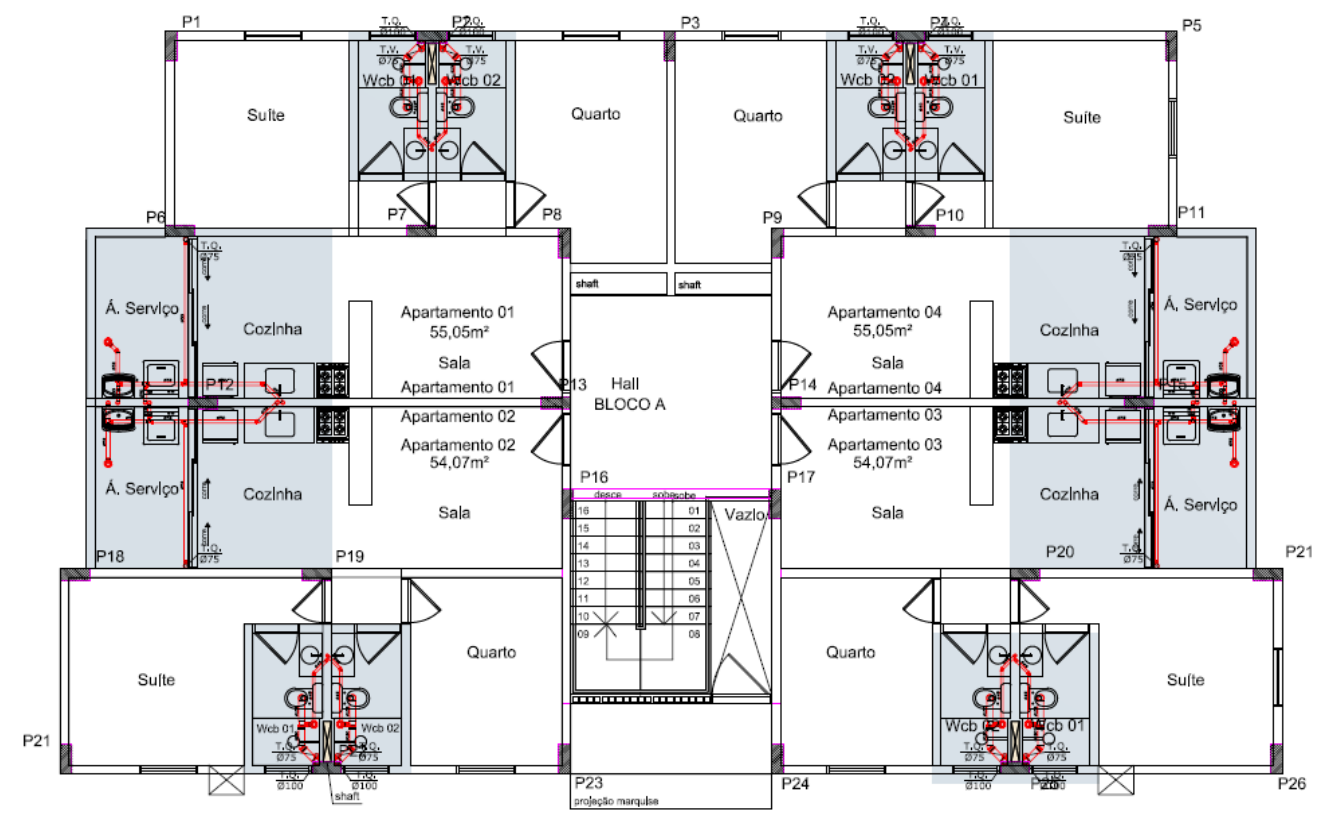

Fonte: Autoria própria

ajustada, impedindo falhas na aplicação da carga; Utilizar câmera fotográfica com melhor resolução e maior velocidade de aquisição de imagens, permitindo resultados mais precisos;

Aumentar a quantidade de ensaios, utilizando mais corpos de prova e com diferentes materiais e geometrias.

Tratando agora do objetivo geral do trabalho, que era analisar a validade do uso da correlação de imagens na mecânica da fratura, é possível concluir que apesar dos resultados inconclusivos para o deslocamento da abertura do entalhe, a referida técnica apresenta grandes potencialidades e vantagens em diferentes aspectos da mecânica da fratura, seja utilizada sozinha ou em conjunto com o clip gage. Podendo ser citadas algumas destas vantagens:

Permite o acompanhamento dos campos de deslocamento e deformação de forma bastante pontual e ao longo de todo o corpo de prova e não tão somente no entalhe;

Acompanha deslocamentos e deformações em todas as direções dos planos;

Permite acompanhar o comportamento 
da fratura ao longo de todo ensaio, auxiliando na determinação do caminho preferencial de propagação, importante em ensaios com juntas soldadas;

A utilização da ferramenta Vector permite determinar anomalias na aplicação da carga;

Não entra em contato com o corpo de prova, evitando interferência nos resultados, porém apresenta a desvantagem de não poder ser utilizada em ensaios cuja configuração prejudique a qualidade da imagem.

Outras potencialidades podem ser observadas por aqueles que se alvitrem a estudar a mecânica da fratura e/ou a correlação de imagens. Em que este trabalho se propõem a ser uma referência inicial para o desenvolvimento desta potente e cheia de potencial ferramenta no estudo da ciência dos materiais.

\section{REFERÊNCIAS}

GRAZIANO, F. P. Compatibilização de projetos. Instituto de Pesquisas tecnológicas - IPT (Mestrado Profissionalizante), São Paulo, 2003.

MELHADO, S. B. O Processo de Projeto no Contexto da Busca de Competitividade. In. Anais do Seminário Internacional - Gestão e Tecnologia na Produção de Edifícios. São Paulo, EPUSP/PCC, 1997, p. 7-51.

MELHADO, S.B. Qualidade do projeto na construção de edifícios: aplicação ao caso das empresas de incorporação e construção. São Paulo: Tese - escola Politécnica da Universidade de São Paulo, 1994.

MIKALDO JR, Jorge, SCHEER, Sergio. Compatibilização ou Engenharia Simultânea: Qual é a melhor solução. 2008. Tese (Mestrado Profissionalizante) - Universidade Federal do Paraná.

MIKALDO JUNIOR, Jorge. Estudo comparativo do processo de compatibilização de projetos em 2D e 3D com uso de TI. 2006. Dissertação (Mestrado Profissionalizante) - Universidade Federal do Paraná.

NOVAES, Celso Carlos. Ações para controle e garantia da qualidade de projetos na construção de edifícios. I WORKSHOP NACIONAL DE GESTÃO DO PROCESSO DE PROJETO NA CONSTRUÇÃO DE EDIFÍCIO, 1998, SÃO CARLOS, BRASIL, 1998, 1998. 5 p.,II. 